\title{
Progressing Green Infrastructure in Europe
}

\author{
M. B. Andreucci \\ Sapienza Università di Roma, Facoltà di Architettura, \\ DATA Department Design, Tecnologia dell'Architettura, \\ Territorio e Ambiente, Rome, Italy
}

\begin{abstract}
The research is focused on the role of GI in supporting the development of a green economy and sustainable land, water and city management. Green Infrastructure is a network of natural and semi-natural spaces and is a broad concept and includes both natural and man-made features, such as parks, land and marine reserves, hedgerows, and wetlands, as well as green roofs, eco-ducts and cycle paths. Although GI has been studied for more than four decades in all countries, it is still a relatively new EU policy instrument and there is not a significant amount of focused research around it. With its multi-functionality, GI is a subject of interest to a variety of stakeholders, such as private business, planning authorities, scientists, the general public and a range of policymakers, with responsibilities ranging from local to a European level. European policy is nowadays acknowledging GI and a communication will be adopted by the EC this year. This presentation, aiming at contributing to the communication of GI potential and successful implementation, will give an overview of the state of the art of GI, including case-study recognition, and will outline questions which the author believe should be answered for GI to progress effectively in Europe. In particular, global competitive gains from GI at an economic, environmental and social level will be explored, and considerations on how multi-functionality can be integrated into methods for quantifying benefits and costs and valuing GI will be developed.
\end{abstract}

Keywords: green infrastructure, green economy, landscape planning, sustainability. 


\section{Introduction}

Today, approximately $75 \%$ of the European population live in urban areas, while still enjoying access to extensive natural or semi-natural landscapes.

The future of Europe cities is, consequently, a matter of great concern. More than a quarter of the European Union's territory has now been directly affected by urban land use; by 2020, approximately $80 \%$ of Europeans will be living in urban areas, while in seven countries the proportion will be $90 \%$ or more (EEA [1]). Although urbanisation can deliver more efficient land use, urban growth, particularly in the form of urban sprawl, is a major threat to biodiversity. Artificial land cover increased by 3.4\% in Europe between 2000 and 2006 - by far the largest increase in all land use categories (CLC [2]). This rapid urbanisation has reinforced concern about the potential effects on biodiversity conservation and quality of human life amongst scientists and policy makers alike.

Moreover, scientific modelling has provided us with many insights on the possible changes in climate Europe may be facing, such as more extreme weather events. Yet many elements will remain difficult to forecast. For example, what will the impact of these changes be at the local level such as the urban area, the farm, the lake, the forest, the river? This is an uncertainty that we will not be able to reduce and the challenge, therefore, is to manage this uncertainty.

The preservation of biodiversity is fundamental to ecosystem health and resilience and is directly linked to the degree of connectivity between the places where species live and the size of the habitats. Because of the long process of habitat fragmentation, especially caused by developments in transport infrastructure, urbanisation, energy generation and agricultural intensification, this loss of connectivity is now in many places the weakest link for species and therefore ecosystem survival. Europe is the continent that has suffered the most in this respect.

\section{The Urban Green Infrastructure}

\subsection{The concept of Urban GI}

"Green infrastructure is the network of natural and semi-natural areas, features and green spaces in rural and urban, terrestrial, freshwater, coastal and marine areas, which together enhance ecosystem health and resilience, contribute to biodiversity conservation and benefit human populations through the maintenance and enhancement of ecosystem services” (Naumann et al. [3]).

While the concept of "ecological networks" is at this stage more widespread, especially in the new Member States, one needs to underline that it cannot be considered an equivalent to 'green infrastructure' given its more restricted scope and purpose. It is also worth noting is that the term 'green infrastructure' as used for several years in UK spatial planning gives a significantly lower priority to 
biodiversity/ecological coherence than the 'green infrastructure' concept as intended by the EC.

Some Green Infrastructure policy initiatives have the creation of urban green spaces as their primary objective, together with delivering services to human populations and/or wild flora and fauna. The principal purpose of this class of Green Infrastructure initiatives is to realise a unique type of element that exists only within urban areas and provides a series of specialised services to urban environments. Green urban areas include any natural elements in towns and cities that provide an ecological or ecosystem service function, such as green parks, green walls and green roofs that host biodiversity and allow ecosystems to function and deliver their services by connecting urban, peri-urban and rural areas. In particular, Green Infrastructure in proximity to urban areas is associated with a high potential in delivering multiple benefits to society (Ecologic [4]).

\subsection{The multi-functionality of GI}

One of the key attractions of GI is its multi-functionality, i.e. its ability to perform several functions and provide several benefits on the same spatial area. These functions can be environmental, such as conserving biodiversity or adapting to climate change, social, such as providing water collection and drainage or green space, and economic, such as supplying jobs and raising property prices. A good example of this multi-functionality is provided by the urban GI of a green roof, which reduces storm water runoff and the pollutant load of the water, while also decreasing the urban heat effect, improving the insulation of the building and providing habitat for a variety of species. It is the multi-functionality of GI that sets it apart from the majority of its 'grey' counterparts, which tend to be designed to perform one function, such as transport or drainage without contributing to the broader environmental, social and economic context (Naumann et al. [3]). GI can therefore be a highly valuable policy tool to promote sustainable development and smart growth by meeting multiple objectives and addressing various demands and pressures (EEA [1]).

\subsection{Recent trends in Urban GI}

A large number of cities have undertaken green infrastructure mapping and studies indicate cities vary considerably in their green infrastructure development.

According to National Audit Office [5] in the United Kingdom, private urban green areas are declining and brown-field sites and public 'waste ground' tend to be the focus of much development.

EU data on the condition of green infrastructure components in urban areas are unavailable, but conditions are likely to be highly variable and context specific.

Fuller and Gaston [6] document a dramatic drop in per capita green space provision in cities with greater population densities. This association appears to involve more people being packed into the urban matrix, rather than buildings 


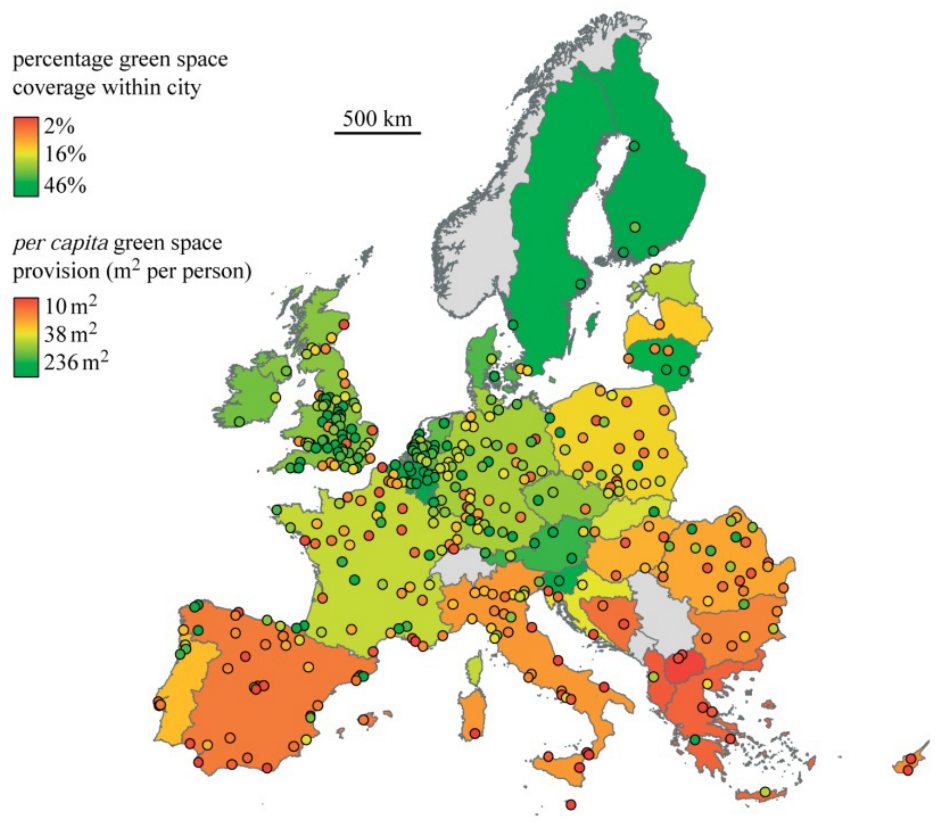

Figure 1: Green space in European cities (Fuller and Gaston [6]). Points representing cities are colored according to proportional coverage by urban green space within the city. Country polygons are colored according to per capita green space provision for its urban inhabitants. Data unavailable for countries shaded grey.

replacing existing green spaces, and as urbanisation reaches extreme levels, the green space network becomes resistant to further compaction.

Those analyses suggest that access to green space could decline rapidly as cities grow, increasing the geographical isolation of people from opportunities to experience nature. More generally, contact with urban biodiversity can be interpreted as a quality of life indicator, distinct from the biological value of an area. Maintaining green space quantity and quality in the face of increasing urbanisation is therefore a pressing global challenge. As cities grow, interactions between people and nature will depend increasingly on landscape quality outside formal green space networks, such as street plantings, or the size, composition and management of backyards and gardens.

Biodiversity levels within cities tend to be highly dependent on the amount, type and diversity of habitats that are present. For example, urban wetlands, abandoned industrial sites, roadside verges, vacant lots and derelict lands, ruins, allotment gardens and cemeteries are increasingly recognised as potential reservoirs of urban biodiversity - together with arboreta, residential gardens and villas, botanic gardens and individual balconies (Heywood [7]). Although there does not seem to be documented evidence that urban green infrastructure initiatives boost biodiversity levels, this can be reliably inferred, where increases 
in habitat quality and quantity occur. The most important types of urban habitat in biodiversity terms are often some types of post-industrial sites (e.g. ash heaps or mineral extraction sites) that have very low nutrient levels, are frequently disturbed, highly acidic or alkaline, or have high levels of heavy metals. Such sites hold few species, but they can have species or communities that are naturally found in habitats such as hot springs or on bare mineral deposits, which are now very rare. Such urban / industrial sites therefore mimic natural sites and may now be the last remaining refuge for some species. The sometimes extreme conditions of cities can also give rise to novel species communities and there are documented examples of genetic changes and the evolution of new taxa (Zerbe et al. [8]). Consequently, although most species are of low nature conservation value, cities can play an important role in hosting certain threatened species and habitats, including some European importance. For example, as a result, some 97 Natura 2000 sites exist in 32 major cities in Europe, sixteen of which are capitals (Sundseth and Raeymaekers [9]).

\subsection{EU policies and current practice for GI implementation}

One of the most effective ways of building up Green Infrastructure is through spatial planning. Policies that adopt a spatial planning approach can improve spatial interactions over a large geographical area - i.e. at local and regional level. Spatial planning entails bringing together different sectors in order to decide on land-use priorities in an integrated and cooperative way.

Significant EU initiatives pursue specific primary objectives [10], including:

(1) to enhance, conserve and restore biodiversity by inter alia increasing spatial and functional connectivity between natural and semi-natural areas and improving landscape permeability and mitigating fragmentation;

(2) to maintain, to strengthen and, where adequate, to restore the good functioning of ecosystems, in order to ensure the delivery of multiple ecosystem and cultural services;

(3) to mitigate and to adapt to climate change, to increase resilience and to reduce the vulnerability to natural disaster risks - floods, water scarcity and droughts, coastal erosion, forest fires, mudslides and avalanches as well as urban heat islands;

(4) to contribute to healthy living, better places to live, provisioning open spaces and recreation opportunity, increasing urban-rural connections, contributing to sustainable transport systems and strengthening the sense of community;

(5) to enhance the societal and cultural link with nature and biodiversity, to acknowledge and to increase the economic value of ecosystem services and to create incentives for local stakeholders and community to deliver them;

where (2), (3), (4) and (5) can be expected to also deliver benefits to biodiversity (i.e. habitat and species protection). 
A wide range of green infrastructure projects and measures exist although they are not always identified as such. Initiatives reported as implementing green infrastructure take place in a variety of contexts. To name just a few:

- use of green infrastructure in and around urban areas, e.g. for microclimate regulation, water provision, recreation, urban biodiversity;

- wetlands and floodplains restored and managed for flood risk management, climate change adaptation/mitigation, biodiversity, increase in overall resilience;

- multi-functional use of green infrastructure in farmland, forests and coastal areas, e.g. provision of food, wood, recreation, biodiversity conservation, etc.

Green infrastructure implementation is characterised by a wide variety of approaches. These include:

- broad-ranging initiatives that target a wide variety of land uses and stakeholders, but also programmes that are highly focused;

- timeframes that vary from a few years to decades;

- a wide range of policy tools and instruments, varying from awarenessraising and stakeholder processes through financial instruments to prescriptive legislative programmes;

- actions that affect a broad range of natural landscape features in multiple ways.

Existing measures generally combine different policy tools and instruments to protect, manage and develop Europe's green infrastructure. While it is generally possible to identify a core tool or instrument around which a green infrastructure implementing measure is structured, green infrastructure implementing measures are almost always a combination of a wider set of tools and instruments.

Most of the 100 green infrastructure initiatives recently analysed (IEEP [5]) in the Member States are led by governments, 15 by other types of organization, principally environmental NGOs, research institutes and businesses. The largest number of initiatives identified corresponded to ecological networks (35) followed, in order of importance, by freshwater and wetland management (15), multi-functional use, coastal zones (11), urban green infrastructure (10), multifunctional use of forests (6), green infrastructure mapping (6) and mitigation of grey infrastructure (4), multi-functional use of farmland (3) and a few others, the majority of which included climate change mitigation and adaptation (8).

The identification of initiatives showed that the green infrastructure concept is not yet being implemented in an integral form. The closest equivalent can be found in Ireland, which is developing an ecosystem approach to integrate the concept of green infrastructure in spatial plans. It should also be noted that the term 'green infrastructure' and its equivalents in other languages does not yet have a commonly accepted scope or definition. In addition to Ireland, the concept is starting to be introduced in other Member States, such as Italy. Luxembourg's landscape plan focuses on "infrastructure verte", which literally means 'green infrastructure'. Interestingly, the French ecological network 
programme "Trame Verte et Bleue" is now officially translated in English as "Green and Blue Infrastructure" and the government's publications are now emphasising the broader benefits of the approach beyond biodiversity conservation. "Green Infrastructure” spatial strategies and plans are being widely developed in England and also in Sweden ("Grönstruktur") and in the Latvian city of Liepaja ("Zạ̦ā infrastruktūra”), but these use the term to refer to a spatial planning model rather than prioritising biodiversity conservation (i.e. species and habitat protection) although the Swedish plans aim at reducing ecological fragmentation.

With regard to biodiversity conservation, the ecological coherence element of green infrastructure is most closely realised within the various ecological network programmes across Europe. In this regard, only a few Member States, such as the Netherlands, Denmark, Luxembourg and Poland, have explicitly included ecological coherence in provisions implementing the EU Strategic Environmental Assessment Directive. The provision of ecosystem services, particularly recreation, water quality and quantity, is another element of green infrastructure that is prominent within the initiatives.

\subsubsection{Selected EU GI initiatives in urban areas}

The following examples are thought to reflect - but not fully cover - the variety of green infrastructure initiatives in European urban areas.

The Regional Plan of Territorial Planning in the Metropolitan Area of Lisbon (Portugal, 2010) is an example of a proactive approach to creating and conserving green urban areas by integrating principles relating to its protection and enhancement into regional spatial planning, in particular by minimising negative impacts and enhancing the positive effects arising from the implementation of projects. The initiative is implemented in the Lisbon Metropolitan Area through the Metropolitan Ecological Network ("Rede Ecológica Metropolitana”, REM). The objectives of the REM are to maintain connectivity features and ecological continuity on the territory and to achieve other environmental goals concerning the stability and quality in the metropolitan area, such as protection of water resources, soil and landscape [11].

The two other examples selected for relevance are the planning of the network of ecological corridors in the Autonomous Community of Madrid (Spain, 2011), and the Green Roofs of Basel (Switzerland, 2006), both using different policy instruments compared to Lisbon. The Spanish initiative aims at creating a metropolitan green ring (suburban green corridors) based on the existing urban and metropolitan parks and focuses on ecosystem service provision and ecosystem resilience, investments for which a rather favourable cost-benefit ratio is reported. The Swiss initiative is funded from an Energy Saving Fund and emphasizes energy-saving benefits. The interesting aspect is that it also delivers key co-benefits such as overall micro-climate regulation, better rainwater runoff management and some biodiversity benefits, leading the assessment of the initiative to conclude to a positive cost-benefit ratio [11].

Other policy initiatives and projects not included in this case analysis also demonstrate the potential of Green Infrastructure to improve urban territorial space. The international GRaBS project, for example, has the objective of 


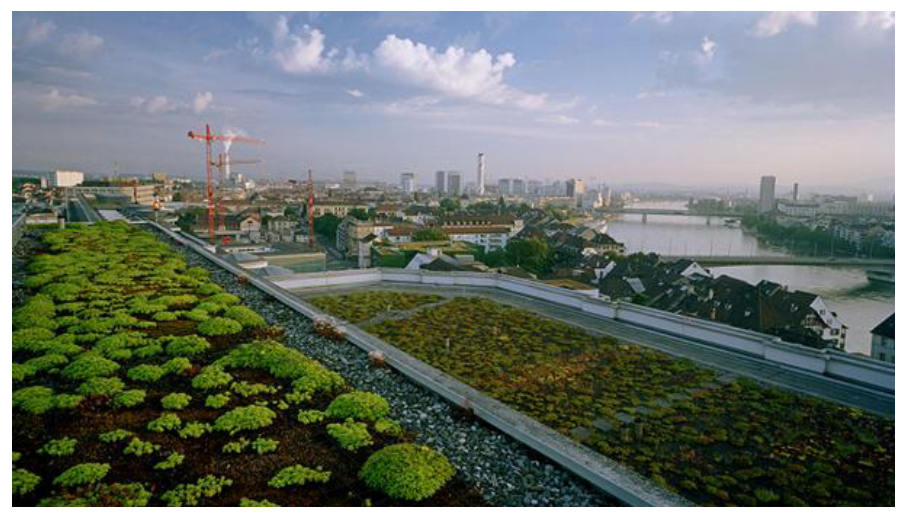

Figure 2: Basel Green Roof, Diane Cook and Len Jenshel, National Geographic Stock [12].

putting in place green and blue infrastructure and facilitating the much-needed exchange of knowledge and experience and the transfer of good practices on climate-change adaptation strategies to local and regional authorities across Europe. The East London Green Grid initiative will improve East London's provision of open space and provide a range of formal and informal recreational uses and landscapes, promoting healthy living and amplifying the public enjoyment of the outdoors. The Third Green Belt of Frankfurt has the intention of creating large-scale green spaces in the context of plans for housing developments. The "Corona Verde” Green Crown Project of Turin promotes both the exceptional value of the metropolitan parks and the royal Savoy residences, together with the traditional rural landscape. The Andalusia Network of Natural Protected Spaces ("RENPA") in Spain is incorporated into the territorial model of Andalusia by considering the peri-urban functions of natural spaces, and a dedicated project, “Green Doors”, has been developed [11].

\section{Summary and conclusions}

With its multi-functionality, GI involves several policy areas, which means it is potentially of interest to a variety of stakeholders, such as private businesses, planning authorities, conservationists, the public and a range of policymakers with responsibilities ranging from the local to the European (Naumann et al. [3]). To ensure GI does fulfil its many functions, the relevant stakeholders need to be involved in its planning, implementation and evaluation.

Good research and monitoring of GI can contribute to the communication of its potential and its successful implementation. Communities can be unaware of the benefits provided by GI or believe it is more expensive or difficult to implement than grey infrastructure (Foster et al. [13]). With several stakeholders involved, a conflict of interests is possible, which again highlights the need for consultation and participation to integrate different values attributed to GI. 
Although GI has been studied since the 1970s in countries including Germany under the guise of 'landscape planning', it is still a relatively new EU policy instrument, which means there is not a large amount of specific research around its multi-functionality when applied to the EU.

There is a body of research on ecosystem assessment and, more recently, on the trade-offs between ecosystem services, which could be applied spatially to the GI concept, for example, in gathering indicators and methods to determine the contribution of different land uses to the promotion of GI.

In their research framework for urban green spaces, James et al. [14] have outlined questions which we can agree should be answered for GI to progress effectively. In particular, they recommend more research on the global competitive gains from GI at an economic, environmental and social level, and on how multidisciplinary considerations can be integrated into methods for quantifying and valuing GI. Within the specific theme 'The Valuation of Urban Green Space', the following four key research questions have been identified:

(i) What global competitive gains are delivered to cities through the provision of high-quality green spaces and how can these gains be sustained/increased through green space planning and management?

(ii) How can trans-disciplinary considerations be integrated into the development of widely accepted methodologies for quantifying and valuing ecosystem services that are provided by urban green spaces?

(iii) How can the multiple 'public good' and 'market' benefits of urban green spaces be valued and built into governance and funding decision support tools?

(iv) How can ecosystem services be given an appropriate valuation so that they can be considered more equitably alongside other urban system functions?

Owing to its multi-functionality, there is no single science or discipline responsible for GI (Benedict and McMahon [15]). GI relies on the theories and practices of numerous scientific and land planning professions, such as conservation biology, landscape ecology, urban and regional planning, geographic analysis, information systems and economists. The nearest integrative scientific discipline accountable for its evolution is 'landscape planning'. Integrated spatial planning can, for instance, guide future infrastructure developments away from sensitive sites and help minimise the risk of further habitat loss and fragmentation.

Since GI has roots in several disciplines, its evaluation will need to reflect this. Research into GI also needs to adjust to different spatial scales as its application can range from individual buildings to neighbourhoods and cities to entire regions (Naumann et al. [3]).

Tools are needed that can simultaneously optimize benefits to biodiversity value, human well-being and economic output, and we urge their development and use in planning future human settlement patterns. 


\section{References}

[1] European Environment Agency (EEA). Urban Sprawl in Europe - The Ignored Challenge, 2006. http://www.eea.europa.eu/publications/eea_report _2006_10

[2] Corine Land Cover, 2006.

[3] Naumann, S., McKenna, D. Kaphengs, T. et al.., Design, Implementation and cost elements of Green Infrastructure projects. Final Report, European Commission: Brussels, 2011.

[4] Ecologic Institute. Background paper: Green Infrastructure - Expert Workshop: Berlin, 2011.

[5] Institute European Environmental Policy (IEEP). Green Infrastructure Implementation and Efficiencies. Final Report; p. 11, 2011. http://www.ieep.eu/publications/2012/03/green-infrastructureimplementation-and-efficiency.

[6] Fuller, R. A. \& Gaston, K. J., The Scaling of green space coverage in European cities. Biology Letters 5, doi: 10.1098/rsbl.2009.0010, p. 353, 2009. www.rsbl.royalsocietypublishing.org.

[7] Heywood, V., The importance of Urban Environments in Maintaining Biodiversity. di Castri, F. \& Younès, T., (eds.), Biodiversity, Science and Development: Towards a New Partnership, CAB International: Wallingford, Oxon, in association with The International Union of Biological Sciences, pp. 543-550, 1996.

[8] Zerbe, S., Maurer, U., Schmits, S. \& Sukopp, H., Biodiversity in Berlin and its potential for nature conservation. Landscape and Urban Planning, 62, pp. 139-148, 2003.

[9] Sundseth, K. \& Raeymaekers, G., Biodiversity in Natura 2000 in urban areas - Nature in cities across Europe: a review of Key issues and experiences, IBGE/BIM: Brussels, 2006.

[10] European Commission DG Environment News Alert Service. http://ec.europa.eu/environment/integration/research/research_news_en.htm

[11] Institute European Environmental Policy (IEEP). Task 4.1: In-Depth Case Analysis; ENV.B.2./SER/2010/0059. www.ieep.eu/assets/903/GI_Case_ Analysis_5_-_Urban_Green_Infrastructure

[12] BBC. http://www.bbc.com/travel/slideshow/20120608-switzerlandshabitats-in- the-sky

[13] Foster, J., Lowe, A., \& Winkelman, S., The value of green infrastructure for urban climate adaptation, The Center for Clean Air Policy: Washington, 2011.

[14] James, P., Tzoulas, K., Adams, M. D. et al., Towards an integrated understanding of green space in the European built environment. Urban Forestry and Urban Greening 8, pp. 65-75, 2009.

[15] Benedict, M. A. \& McMahon, E. T., Green Infrastructure: Smart Conservation for the $21^{\text {st }}$ Century. Renewable Resources Journal 20(3), pp. 12-17, 2002. 